Rev. Bras. Saúde Prod. Anim., Salvador, v.16, n.1, p.118-129 jan./mar., 2015 http://www.rbspa.ufba.br

\title{
Bagaço de cana-de-açúcar como volumoso exclusivo em dietas para ovinos
}

\author{
Sugar cane bagasse as roughage in sheep diet
}

SILVA, Aghata Elins Moreira da ${ }^{1}$; LIRA, Amanda Tenório de ${ }^{1}$; FERREIRA, Marcelo de Andrade ${ }^{2}$; BARROS, Leonardo José Assis de ${ }^{1}$; MELO, Tobias Tobit de Barros ${ }^{1}$; SIQUEIRA, Thamires Damascena Quirino'; SOARES, Luciana Felizardo Pereira ${ }^{3}$; COSTA, Cleber Tiago Ferreira ${ }^{4}$

\author{
${ }^{1}$ Universidade Federal Rural de Pernambuco, Recife, Pernambuco, Brasil. \\ ${ }^{2}$ Universidade Federal Rural de Pernambuco, Departamento de Zootecnia, Recife, Pernambuco, Brasil. \\ ${ }^{3}$ Universidade Federal Rural de Pernambuco, Programa Nacional de Pós-Doutorado, Recife, \\ Pernambuco, Brasil. \\ ${ }^{4}$ Universidade Federal Rural de Pernambuco, Programa de Doutorado Integrado em Zootecnia \\ UFRPE/UFC/UFPB, Recife, Pernambuco, Brasil. \\ *Endereço para correspondência: 1fpmsoares@gmail.com
}

\section{RESUMO}

Objetivou-se avaliar o efeito de diferentes proporções de concentrado e bagaço de cana-deaçúcar como volumoso exclusivo em dietas para ovinos. Os consumos de matéria seca, matéria orgânica, proteína bruta, carboidratos não fibrosos e nutrientes digestíveis totais expressos em $\mathrm{kg} / \mathrm{dia}$, aumentaram linearmente com o aumento da proporção de concentrado na dieta. O mesmo comportamento foi observado para a digestibilidade da matéria seca. O que ocorreu de forma contrária para a digestibilidade da fibra em detergente neutro, que diminuiu com os maiores níveis de concentrado. Com o aumento das proporções de concentrado nas dietas experimentais, foi observado efeito quadrático no tempo despendido com ruminação, alimentação e ócio, e nas concentrações de ácido acético, propiônico e butírico no rúmen. Maiores proporções de concentrado associado ao bagaço de cana-de-açúcar in natura podem ser utilizadas em dietas para ovinos.

Palavras-chave: consumo, digestibilidade, parâmetros ruminais

\section{SUMMARY}

This study aimed to evaluate the effect of different proportions of concentrate and sugar cane bagasse as roughage exclusive for sheep. The dry matter intake, organic matter, crude protein, non-fibrous carbohydrates and total digestible nutrients in $\mathrm{kg} /$ day, increased linearly with increasing proportion of concentrate in the diet. The same behavior was observed for dry matter digestibility. It occurred in a manner contrary to the digestibility of neutral detergent fiber that decreased with the higher levels of concentrate. With the increase of the proportion of concentrate in the diets, quadratic effect was observed to time of rumination, feeding and idleness, and the of concentrations of acetic, propionic and butyric acid in the rumen. Higher proportions of concentrate associated with sugar cane bagasse in nature can be used in diets.

Keywords: intake, digestibility, ruminal parameters

\section{INTRODUÇÃO}

Recentemente, a mesorregião do Agreste pernambucano e todo $\mathrm{o}$ Nordeste brasileiro passaram por uma grande seca, que resultou em perdas econômicas e sociais mais graves do que as observadas em secas anteriores, em grande parte devido ao aumento do efetivo ovino e do número de fazendas que se dedicam à essa atividade, a maioria da agricultura familiar. As alternativas para amenizar a situação no 
Rev. Bras. Saúde Prod. Anim., Salvador, v.16, n.1, p.118-129 jan./mar., 2015 http://www.rbspa.ufba.br

curto e médio prazo são poucas, pelas dificuldades de produção de volumosos na região, seja pelas restrições físicoquímicas dos solos, de recurso hídricos e climáticas.

O bagaço da cana-de-açúcar é um volumoso de uso generalizado na região, pela proximidade com as regiões produtoras de cana-de-açúcar, e ao ser adicionado em dietas de ruminantes em conjunto com a palma forrageira, contorna a falta de efetividade da fibra desta cactácea. Ferreira et al. (2009) indicam o uso do bagaço na proporção de $30 \%$ e de $40-50 \%$ de palma forrageira com base na matéria seca tanto para vacas leiteiras como para fêmeas em crescimento. São escassos os trabalhos que utilizaram o bagaço como alimento exclusivo para as várias categorias que compõem o rebanho ovino. O alto custo da palma no momento atual praticamente inviabiliza o seu uso associado ao bagaço de cana.

Para que os sistemas de produção de ovinos sejam economicamente viáveis e competitivos é necessário, entre outros fatores, proporcionar ao animal condições de exteriorizar o máximo desempenho de suas potencialidades genéticas através do fornecimento de alimentação balanceada (SANTELLO et al., 2006). Em dietas com alta proporção de ingredientes concentrados, é seguro o uso de um teor mínimo de fibra, capaz de estimular a mastigação e permitir ambiente ruminal adequado para não prejudicar o desempenho animal (MENDES et al., 2010).

O tratamento físico ou químico do bagaço de cana de açúcar não tem trazido benefícios interessantes na alimentação de bovinos (TEIXEIRA et al., 2007) mesmo associado a palma (FERREIRA et al., 2009). Assim, a alternativa é encontrar uma relação volumoso:concentrado que maximiza o consumo e a digestão da matéria seca maximizando o desempenho.

Objetivou-se avaliar o efeito de diferentes proporções de concentrado e o bagaço de cana-de-açúcar como volumoso exclusivo em dietas para ovinos.

\section{MATERIAL E MÉTODOS}

O experimento foi conduzido nas dependências do Departamento de Zootecnia da Universidade Federal Rural de Pernambuco, no setor de Caprino-ovinocultura da Universidade Federal Rural de Pernambuco.

Foram utilizados cinco ovinos, castrados, sem padrão racial definido, com peso corporal (PC) médio inicial de $40 \mathrm{~kg}$, com fístula permanente no rúmen. Os animais foram mantidos em baias individuais cobertas, com piso de concreto, dispostas com comedouro e com acesso irrestrito a água.

A alimentação foi constituída por bagaço de cana e diferentes níveis de concentrado, e fornecida ad libitum na forma de ração completa, às $08 \mathrm{~h} 00 \mathrm{e}$ $16 \mathrm{~h} 00$, permitindo-se aproximadamente $10 \%$ de sobras. Os tratamentos consistiram de diferentes níveis $(40,50$; $60 ; 70$ e $80 \%$ ) de concentrado em dietas tendo o bagaço de cana como volumoso (Tabelas 1, 2 e 3 ).

$\mathrm{O}$ experimento foi constituído de cinco períodos experimentais com 15 dias de duração, sendo os sete primeiros destinados à adaptação dos animais às dietas experimentais e oito dias de coletas de dados e amostras.

Os teores de matéria seca (MS; Método INCT-CA G-003/1), matéria mineral (MM; Método INCT-CA M-001/1), proteína bruta (PB; Método INCT-CA N$001 / 1$ ), extrato etéreo (EE; Método INCT-CA G-004/1), fibra em detergente neutro (FDN; Método INCT-CA F- 
Rev. Bras. Saúde Prod. Anim., Salvador, v.16, n.1, p.118-129 jan./mar., 2015 http://www.rbspa.ufba.br ISSN 15199940

002/1), fibra em detergente ácido (FDA; Método INCT-CA F-004/1) e fibra em detergente neutro indigestível (INCT-CA F-009/1) foram determinadas conforme Detmann et al. (2012).

Para estimativa de consumo de matéria seca e nutrientes foram tomadas amostras da dieta fornecida e das sobras durante sete dias consecutivos de cada período experimental. Essas amostras foram identificadas, pesadas $\mathrm{e}$ armazenadas em freezer a $-20^{\circ} \mathrm{C}$. Posteriormente, foram feitas amostras compostas por período e animal. Todas as amostras foram secas em estufa de circulação forçada $\left(55^{\circ} \mathrm{C} / 72\right.$ horas $) \mathrm{e}$ moídas em moinho tipo Willey, passando por peneiras com crivo de $1 \mathrm{~mm}$ de diâmetro, para posterior determinação da composição química.

Para determinação da FDN foram utilizados sacos de tecido não tecido (TNT, $100 \mathrm{~g} / \mathrm{m}^{2}$; CASALI et al., 2009). Em todas as amostras, a FDN foi corrigida para cinzas e proteína. Para correção de cinzas o resíduo da digestão da amostra em detergente neutro foi incinerado em forno mufla com temperatura a $550^{\circ} \mathrm{C}$ por 2 horas (Método INCT-CA M-002/1), e para a correção para proteína o resíduo foi submetido à análise de proteína bruta (Método INCT-CA N-004/1).

Tabela 1. Proporção dos ingredientes das dietas experimentais

\begin{tabular}{lccccc}
\hline \multirow{2}{*}{ Item (g/kg MS) } & 40 & 50 & 60 & 70 & 80 \\
\cline { 2 - 5 } & 600 & 500 & 400 & 300 & 200 \\
Bagaço de cana & 152 & 152 & 152 & 152 & 152 \\
Farelo de soja & 220 & 323 & 426 & 529 & 632 \\
Milho & 13 & 10 & 7 & 4 & 1 \\
Ureia & 10 & 10 & 10 & 10 & 10 \\
Minerais & \multicolumn{5}{c}{ Proporção de Concentrado } \\
Sal comum & 5 & 5 & 5 & 5 & 5 \\
\hline${ }^{1}$ Composição química do sal mineral:120 $\mathrm{g} \mathrm{de} \mathrm{Ca} \mathrm{kg}^{-1} ; 85 \mathrm{~g} \mathrm{de} \mathrm{P} \mathrm{kg}^{-1} ; 16 \mathrm{~g} \mathrm{de} \mathrm{S} \mathrm{kg}^{-1} ; 148 \mathrm{~g} \mathrm{de} \mathrm{Na} \mathrm{kg}^{-1}$; &
\end{tabular}

Tabela 2. Composição nutricional dos ingredientes

\begin{tabular}{|c|c|c|c|}
\hline Item ( $\mathrm{g} / \mathrm{kg}$ na MS) & $\begin{array}{l}\text { Bagaço de cana-de- } \\
\text { açúcar }\end{array}$ & Milho & Farelo de soja \\
\hline Matéria Seca* & 910,7 & 860,1 & 921,2 \\
\hline Matéria Orgânica ${ }^{1}$ & 975,8 & 921,7 & 988,3 \\
\hline Proteína Bruta $^{1}$ & 16,7 & 95,0 & 490,0 \\
\hline Extrato Etéreo $^{1}$ & 11,1 & 41,4 & 13,9 \\
\hline Fibra em detergente neutro ${ }^{1}$ & 759,3 & 171,6 & 162,7 \\
\hline Fibra em detergente neutro $\mathrm{cp}^{2}$ & 733,3 & 145,9 & 122,0 \\
\hline Fibra em detergente ácido ${ }^{1}$ & 445,8 & 439,0 & 69,3 \\
\hline Carboidratos totais ${ }^{1}$ & 947,8 & 838,5 & 403,4 \\
\hline Carboidratos não fibrosos ${ }^{1}$ & 188,4 & 666,9 & 240,7 \\
\hline $\mathrm{PIDN}^{1,2}$ & 7,6 & 16,6 & 32,6 \\
\hline $\mathrm{FDNi}^{1,3}$ & 526,5 & 28,5 & 34,5 \\
\hline
\end{tabular}

${ }^{*} \mathrm{~g} / \mathrm{kg}$ na matéria natural, ${ }^{1} \mathrm{~kg} / \mathrm{kg}$ de $\mathrm{MS},{ }^{2}$ corrigido para cinzas e proteína, ${ }^{2}$ Proteína insolúvel em detergente neutro, ${ }^{3}$ Fibra em detergente neutro indigestível. 
Rev. Bras. Saúde Prod. Anim., Salvador, v.16, n.1, p.118-129 jan./mar., 2015 http://www.rbspa.ufba.br ISSN 15199940

Tabela 3. Composição química das dietas experimentais

\begin{tabular}{lccccc}
\hline \multirow{2}{*}{ Item } & \multicolumn{5}{c}{ Proporções de Concentrado (\%) } \\
\cline { 2 - 5 } & 40 & 50 & 60 & 70 & 80 \\
\hline Matéria Seca* $^{*}$ & 902,6 & 896,6 & 891,6 & 886,5 & 880,9 \\
Matéria Orgânica $^{1}$ & 939,7 & 936,9 & 933,9 & 930,9 & 928,0 \\
Proteína Bruta $^{1}$ & 139,9 & 140,0 & 140,2 & 140,3 & 140,5 \\
Extrato Etéreo $^{1}$ & 17,8 & 20,8 & 23,9 & 27,0 & 30,1 \\
Fibra em detergente neutro $_{\text {cp }}{ }^{2}$ & 494,1 & 437,6 & 379,7 & 321,5 & 264,2 \\
Fibra em detergente ácido $^{1}$ & 289,0 & 250,2 & 210,4 & 170,4 & 131,1 \\
Carboidratos não fibrosos $^{1}$ & 287,9 & 338,5 & 390,1 & 442,1 & 493,2 \\
FDNi $^{1}$ & 327,4 & 277,7 & 228,0 & 178,3 & 128,6 \\
\hline
\end{tabular}

* (g/kg na matéria natural), ${ }^{1} \mathrm{~g} / \mathrm{kg}$ na $\mathrm{MS},{ }^{2}$ corrigida para cinzas e proteína.

Os carboidratos totais foram calculados segundo Sniffen et al. (1992), em que: $\mathrm{CHOT}=100-(\% \mathrm{~PB}+\% \mathrm{EE}+$ \%Cinzas). Os teores de carboidratos não fibrosos (CNF) foram estimados segundo Detmann \& Valadares Filho (2010): $\mathrm{CNF}=100-[\mathrm{MM}+\mathrm{EE}+$ FDNcp + (PB-PBu+U)] em que: $\mathrm{CNF}=$ teor de carboidratos não fibrosos; $\mathrm{MM}=$ teor de matéria mineral; $\mathrm{PB}=$ teor de proteína bruta; $\mathrm{EE}=$ teor de extrato etéreo; $\mathrm{FDNcp}=$ teor de fibra em detergente neutro corrigida para cinzas e proteína; $\mathrm{PBu}=$ proteína bruta oriunda da ureia; e $U=$ teor de ureia.

Foi realizada coleta total de fezes com auxílio de bolsas coletora fixada nos animais, durante cinco dias. $\mathrm{O}$ coeficiente de digestibilidade de cada componente da dieta foi estimado utilizando-se a seguinte equação: $\mathrm{CD}=$ (Quantidade consumida-Quantidade excretada nas fezes)*100/Quantidade consumida. Os nutrientes digestíveis totais (NDT) foram estimados de acordo com a seguinte formula: NDT $(\%)=$ $\mathrm{PBD} \%+\mathrm{FDNcpD} \%+\mathrm{CNFD} \%+(2,25$ $\times \mathrm{EED} \%$ ).

Foram retiradas alíquotas de líquido ruminal para avaliação do $\mathrm{pH}$ e ácidos graxos de cadeia curta (AGCC, acetato, propionato e butirato). As amostras foram coletadas manualmente na interface líquido:sólido do ambiente ruminal através da fístula, logo antes da alimentação zero, duas, quatro e seis horas após alimentação. Posteriormente foram filtradas com pano de algodão e submetidas à avaliação do $\mathrm{pH}$ com auxílio de potenciômetro digital. Em seguida, uma alíquota de $20 \mathrm{~mL}$ foi fixada com $5 \mathrm{~mL}$ de ácido metafosfórico $(25 \% \mathrm{v} / \mathrm{v})$ para avaliação de AGCC em cromatógrafo modelo CGMaster, com detector de ionização por chama e injetor split/splitless e colunas capilares BPX-70, 60m x 0,25mm x $0,25 \mu \mathrm{m}$ (sílica fundida). Fab.: SGE, Austrália.

Dados referentes ao comportamento animal foram coletados no primeiro dia de coleta de cada período através do método de varredura instantânea, durante um período de 24 horas, a intervalos de 10 minutos, utilizando-se a metodologia desenvolvida por Johnson \& Combs (1991). As variáveis comportamentais avaliadas foram tempo de alimentação, ócio e ruminação.

$\mathrm{O}$ experimento foi implementado e analisado, segundo delineamento em quadrado latino 5 x 5, através do modelo: $Y_{i j k}=\mu+S_{i}+A_{j}+P_{k}+\varepsilon_{i j k}$, em que: $Y_{\mathrm{ijk}}=$ variável resposta mensurada no animal $\mathrm{j}$, durante o período $\mathrm{k}$, submetido ao tratamento i; $\mu=$ constante geral; $\mathrm{S}_{\mathrm{i}}=$ efeito do tratamento $\mathrm{i}$ (efeito fixo); $\mathrm{Aj}=$ efeito do 
Rev. Bras. Saúde Prod. Anim., Salvador, v.16, n.1, p.118-129 jan./mar., 2015 http://www.rbspa.ufba.br ISSN 15199940

animal $\mathrm{j}$ (efeito aleatório); $\mathrm{Pk}=$ efeito do período experimental $\mathrm{k}$ (efeito aleatório); e cijk = erro aleatório nãoobservável, pressuposto de distribuição normal.

Os dados foram submetidos à análise de variância, utilizando-se o procedimento PROC MIXED do programa SAS, (STATISTICAL ANALISYS SYSTEM, 2002) utilizando nível de $5 \%$ de probabilidade para o erro tipo I.

\section{RESULTADOS E DISCUSSÃO}

Os consumos de matéria seca, matéria orgânica, proteína bruta, carboidratos não fibrosos e nutrientes digestíveis totais, aumentaram linearmente com o aumento da proporção de concentrado na dieta (Tabela 4). Os maiores consumos de matéria seca e nutrientes, com exceção da FDN, foram verificados quando os animais consumiram a dieta com $80 \%$ de concentrado $(26,42 \%$ de FDN e $49,32 \%$ de CNF), logo, mais digestível e com maior taxa de passagem (Tabela 4).

O consumo de fibra em detergente neutro ( $\mathrm{kg} /$ dia e \% PC) não foi influenciado pela inclusão de concentrado (Tabela 4). Comportamento que se deve ao aumento no consumo de matéria seca e diminuição nos teores de FDN das dietas (Tabela 3), com a redução da proporção de bagaço de cana-de-açúcar.

Tabela 4. Consumo de nutrientes em ovinos recebendo diferentes proporções de concentrado

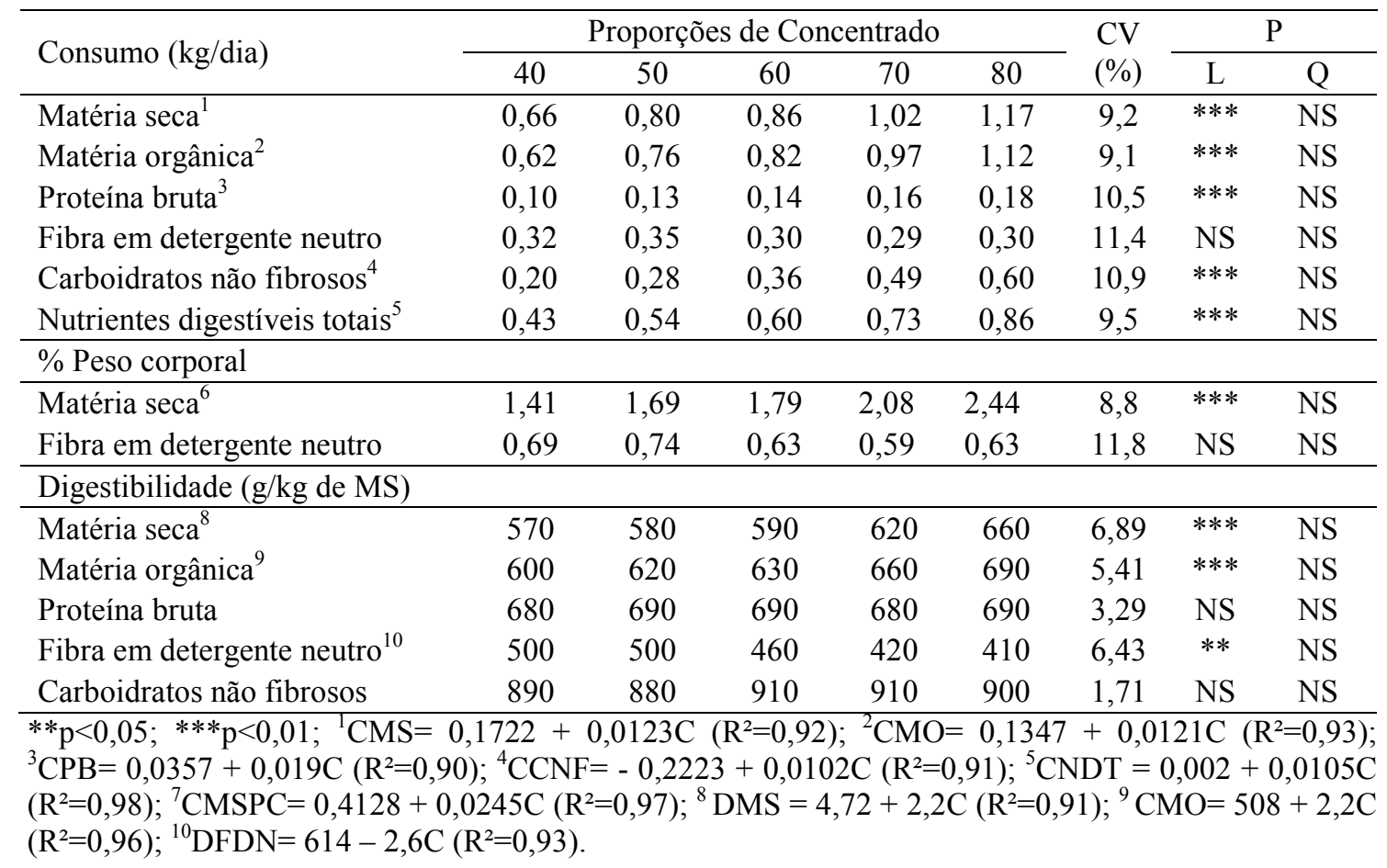

O consumo de dietas com altos teores de fibra é controlado por fatores físicos, como a taxa de passagem e enchimento ruminal. Segundo Sampaio et al. (2009), um dos principais entraves ao consumo voluntário constitui a alta participação de fibra em detergente neutro indigestível (FDNi), principalmente 
Rev. Bras. Saúde Prod. Anim., Salvador, v.16, n.1, p.118-129 jan./mar., 2015 http://www.rbspa.ufba.br ISSN 15199940

quando a forragem apresenta baixa qualidade. Particularmente, para o bagaço da cana-de-açúcar, o efeito de repleção ruminal da FDNi representa o principal entrave para se maximizar o consumo de FDN (OLIVEIRA et al., 2011). Com a diminuição na participação do bagaço de cana nas dietas a proporção de FDNi diminuiu consideravelmente (327,4 a 128,6g/kg de MS; Tabela 3).

Apesar da conhecida influência da quantidade de fibra na dieta sobre consumo de alimento e a fermentação ruminal, são escassas as informações sobre o nível ótimo, máximo e mínimo de fibra para a dieta de ovinos e que nenhum dos sistemas de alimentação de ovinos considera este aspecto.

A ingestão de NDT aumentou linearmente com o nível de concentrado, visto que a adição de concentrado às dietas contribui positivamente para a digestibilidade dos nutrientes.

Os coeficientes de digestibilidade da matéria seca e matéria orgânica (Tabela 4) aumentaram linearmente com o aumento dos níveis de concentrado na dieta. $\mathrm{O}$ aumento linear observado na digestibilidade da matéria seca e matéria orgânica provavelmente ocorreu devido à maior proporção de carboidratos não fibrosos. Em geral, a digestibilidade aparente dos carboidratos não fibrosos é maior do que a digestibilidade dos carboidratos estruturais (CHIZZOTTI et al., 2010).

$\mathrm{O}$ que ocorreu de forma contrária para a digestibilidade da fibra em detergente neutro, que diminuiu com os maiores níveis de concentrado. A adição de amido promove competição de nutrientes entre grupos da microbiota ruminal, resultando em maior proliferação dos microrganismos quando ocorre maior disponibilidade de carboidratos solúveis no rúmen (MERTENS \& LOFTEN, 1980). Nessa condição, os microrganismos que degradam carboidratos não fibrosos apresentam taxa de crescimento superior aos que degradam a fibra (CABRAL et al., 2011).

A inclusão de altas proporções de carboidratos não fibrosos na dieta, os quais tem altas taxas de degradação, geralmente resulta em queda do $\mathrm{pH}$ e da digestibilidade da fibra (DIJKSTRA et al., 2012). O pH crítico, abaixo do qual a degradação da fibra é prejudicada é de aproximadamente 6,0-6,3 (MOURIÑO et al., 2001). Palmonari et al. (2010), usando técnicas moleculares mostraram que vacas com $\mathrm{pH}$ 6,1 podem manter populações de bactérias celulolíticas normais. Em determinados períodos do dia, o pH esteve abaixo dos limites acima citados, principalmente nas dietas com maior participação de concentrado (Figura 3).

Os componentes fibrosos representam uma fração significante da dieta dos herbívoros. O bagaço de cana-de-açúcar possui em sua composição a celulose, a hemicelulose e a lignina como principais componentes (GOUVEIA et al., 2009). A lignina é o componente mais reconhecido por limitar a digestão dos polissacarídeos fibrosos no rúmen (FUKUSHIMA et al., 2001). De acordo com esse autor, os carboidratos fibrosos nem sempre são acessados pelos microrganismos ruminais devido à presença desses compostos fenólicos, que formam uma barreira física para a ação dos sistemas enzimáticos microbianos.

Não houve alteração na digestibilidade dos carboidratos não fibrosos e proteína bruta (Tabela 4). Os carboidratos não estruturais possuem coeficiente de digestibilidade aparente acima de 90\% (MORENO et al., 2010) por apresentarem disponibilidade nutricional rápida e completa no trato gastrintestinal dos ruminantes. Estas considerações sugerem maior ingestão de matéria seca 
Rev. Bras. Saúde Prod. Anim., Salvador, v.16, n.1, p.118-129 jan./mar., 2015 http://www.rbspa.ufba.br ISSN 15199940

em rações que possuem maiores quantidade de concentrado.

Com o aumento das proporções de concentrado nas dietas experimentais, foi observado efeito quadrático no tempo despendido com ruminação, alimentação e ócio (Tabela 5). Os tempos máximos de alimentação e ruminação foram estimados em 3,87 horas com 57,44\%; e 9,30 horas com $51,14 \%$ de concentrado, respectivamente. O tempo mínimo em ócio foi estimado em 10,8 horas com $54,1 \%$ de concentrado.

Tabela 5. Comportamento ingestivo animal em ovinos recebendo diferentes proporções de concentrado

\begin{tabular}{|c|c|c|c|c|c|c|c|c|}
\hline \multirow{2}{*}{ Tempo (horas) } & \multicolumn{5}{|c|}{ Proporções de Concentrado } & \multirow{2}{*}{ CV $(\%)$} & \multicolumn{2}{|c|}{$\mathrm{P}$} \\
\hline & 40 & 50 & 60 & 70 & 80 & & $\mathrm{~L}$ & $\mathrm{Q}$ \\
\hline Alimentação & 3,23 & 4,20 & 3,70 & 3,63 & 3,20 & 13,32 & NS & $* *$ \\
\hline Ócio & 11,96 & 10,10 & 11,16 & 12,13 & 13,45 & 9,29 & NS & $* *$ \\
\hline Ruminação & 8,86 & 9,70 & 9,16 & 8,23 & 7,33 & 12,56 & NS & $*$ \\
\hline
\end{tabular}

A atividade de mastigação é uma característica que reflete as propriedades físicas e químicas dos alimentos (MERTENS, 1997). Devido à forma física do bagaço de cana-deaçúcar, os animais demoram mais tempo se alimentando, e após o seu consumo o componente que permanece no cocho é o concentrado, alimento de fácil apreensão pelos animais, levando a menor tempo de alimentação. Desse modo, há um pico no tempo de alimentação e após isso, uma queda, fato que justifica o comportamento quadrático do tempo total de alimentação. Este comportamento, também foi refletido no tempo de ruminação. O tempo em ócio foi consequência do comportamento observado para os tempos despendidos com alimentação e ruminação.

O tempo de ruminação é influenciado pelo teor de fibra na dieta. Assim, quanto maior a participação de fibra na dieta, maior será o tempo necessário para que o processo de ruminação seja concluído. De acordo com Welch (1982), o limite fisiológico para a atividade de ruminação é de dez horas por dia. Dessa forma, o tempo gasto pelos animais para ruminar não limitou a ingestão de alimentos.

Para as concentrações de AGCC, relação acetato: propionato e $\mathrm{pH}$ não houve efeito da interação entre a proporção concentrado e tempo (Tabela 6). Foram observados efeitos quadráticos da proporção de concentrado na dieta sobre o ácido acético, propiônico e butírico. No entanto, a razão acetato: propionato não foi influenciada pelo tempo e pelo tratamento.

As concentrações máximas para o ácido acético, butírico e propiônico foram observadas entre 5,45 e 4,50 horas após a alimentação (Figura 1). As concentrações dos ácidos graxos de cadeia curta podem estar relacionadas com a digestibilidade do amido do grão de milho, além da diminuição dos teores de FDN das dietas (Tabela 3), o que coincide com a redução do $\mathrm{pH}$ ruminal causado pela rápida fermentação dos carboidratos não fibrosos (MOULD \& ORSKOV, 1983). 
Rev. Bras. Saúde Prod. Anim., Salvador, v.16, n.1, p.118-129 jan./mar., 2015 http://www.rbspa.ufba.br ISSN 15199940

Tabela 6. Concentração de ácidos graxos de cadeia curta e pH ruminal em ovinos recebendo diferentes proporções de concentrado

\begin{tabular}{|c|c|c|c|c|c|c|c|c|c|c|}
\hline \multirow{2}{*}{ Item } & \multicolumn{5}{|c|}{ Proporções de concentrado } & \multicolumn{2}{|c|}{ Tratamento } & \multicolumn{2}{|c|}{ Tempo } & \multirow{2}{*}{ Trat*tempo } \\
\hline & 40 & 50 & 60 & 70 & 80 & $\mathrm{~L}$ & $\mathrm{Q}$ & $\mathrm{L}$ & $\mathrm{Q}$ & \\
\hline Acetato $(\mu \mathrm{mol} / \mathrm{dL})^{1}$ & 51,6 & 66,3 & 54,8 & 48,8 & 48,8 & NS & NS & NS & $* * *$ & NS \\
\hline Propionato $(\mu \mathrm{mol} / \mathrm{dL})^{2}$ & 15,2 & 14,7 & 18,0 & 16,6 & 15,0 & NS & NS & NS & $* *$ & NS \\
\hline Butirato $(\mu \mathrm{mol} / \mathrm{dL})^{3}$ & 6,3 & 6,2 & 7,4 & 7,1 & 6,5 & NS & NS & NS & $* *$ & NS \\
\hline Acetato:propionato & 3,4 & 4,5 & 3,1 & 2,9 & 3,3 & NS & NS & NS & NS & NS \\
\hline $\mathrm{pH}^{4,5}$ & 6,8 & 6,7 & 6,4 & 6,2 & 6,0 & $* * *$ & NS & NS & $* * *$ & NS \\
\hline
\end{tabular}

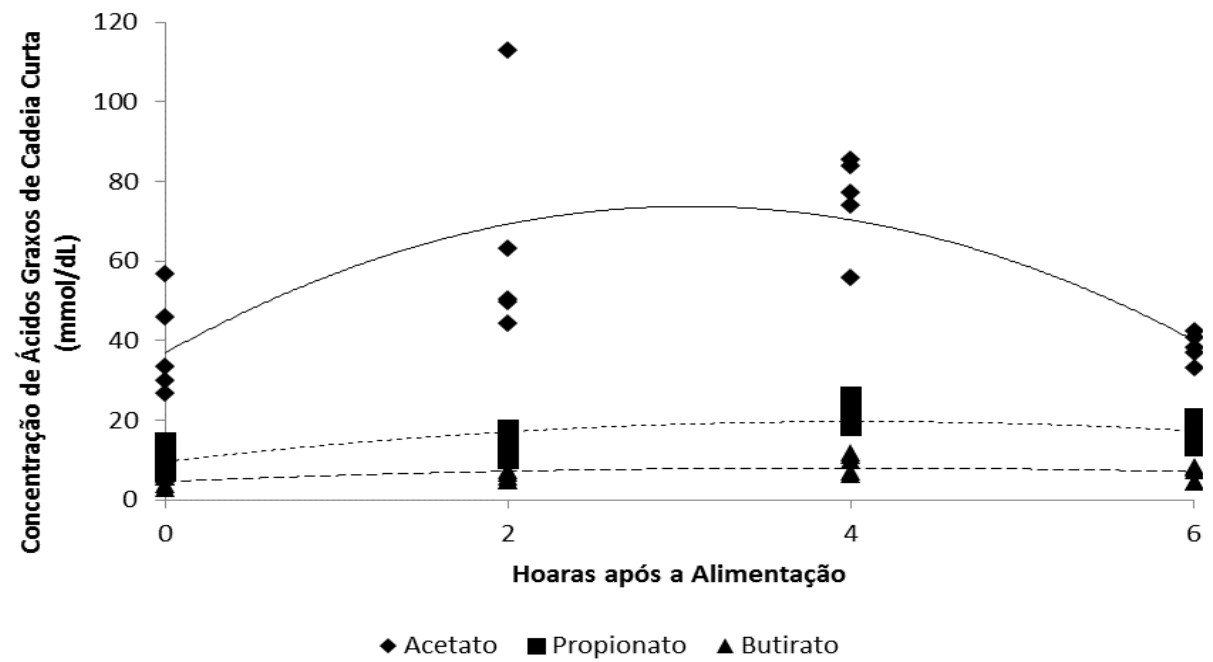

Figura 1. Ácidos graxos de cadeia curta do líquido ruminal em diferentes tempos de coleta em ovinos recebendo diferentes proporções de concentrado

Os animais alimentados com as maiores proporções de concentrado apresentaram decréscimo linear do $\mathrm{pH}$ ruminal (Figura 2). Estudos anteriores (TRIPATHI, et al., 2007) também indicaram declínio no $\mathrm{pH}$ do líquido ruminal em dietas com alta proporção de alimentos concentrados. Diminuição da ruminação e salivação normalmente está associada a dietas com altos teores concentrado (Tabela 5) e consequente redução da capacidade tampão, juntamente com a rápida degradação microbiana de carboidratos solúveis e consequente produção de ácidos graxos de cadeia curta no ambiente, resultam em queda de $\mathrm{pH}$ ruminal (TRIPATHI et al., 2007).

$\mathrm{O}$ efeito de tempo de amostragem sobre o $\mathrm{pH}$ ruminal foi significativo (Tabela 6; Figura 3), mostrando comportamento quadrático do $\mathrm{pH}$, em função do tempo de coleta. $\mathrm{O} \mathrm{pH}$ ruminal é regulado por um sistema complexo que depende do nível de fibra na dieta, do resultado líquido entre a produção e a absorção dos ácidos graxos, do fluxo de saliva e da sua capacidade de tamponamento do rúmen. 
Rev. Bras. Saúde Prod. Anim., Salvador, v.16, n.1, p.118-129 jan./mar., 2015 http://www.rbspa.ufba.br ISSN 15199940

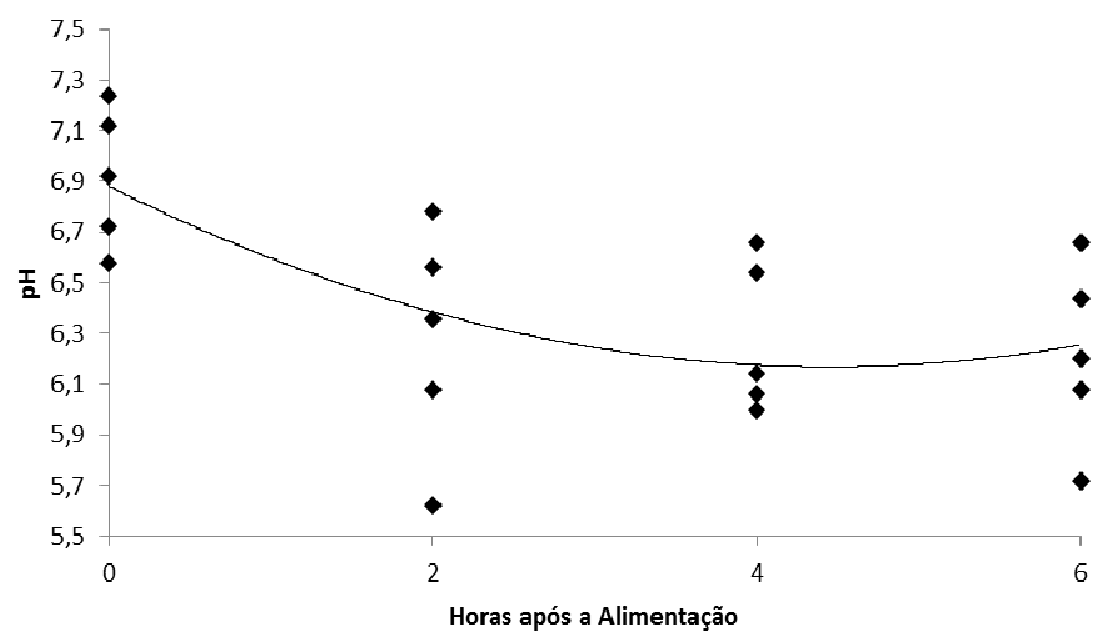

Figura 2. $\mathrm{pH}$ do líquido ruminal em diferentes tempos de coleta em ovinos recebendo diferentes proporções de concentrado

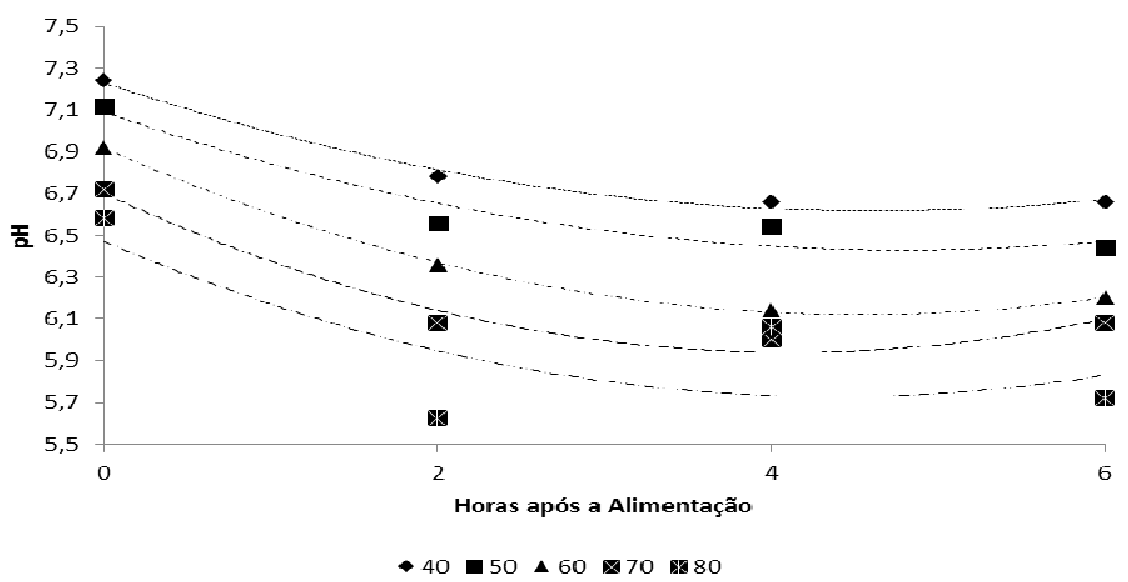

Figura 3. pH do líquido ruminal em diferentes tempos de coleta em ovinos recebendo diferentes proporções de concentrado

A interação entre os níveis de concentrado e os tempos de coleta não foi significativa. Mesmo assim, na Figura 3 são mostrados os comportamentos na variação do $\mathrm{pH}$ para melhor visualização da amplitude e dos valores mínimos de $\mathrm{pH}$ verificados, que poderiam ter contribuído pelo comportamento verificado para a digestibilidade da fibra (Tabela 4). Os valores mínimos de $\mathrm{pH}$ foram, 6,62; 6,$40 ; 6,12 ; 5,94$ e 5,72 às 4,$61 ; 4,81 ;$ 4,$53 ; 4,10$ e 4,38 horas após a alimentação para os níveis 40; 50; 60; 70 e $80 \%$ de concentrado.
O primeiro limiar de vulnerabilidade do epitélio ruminal ocorre quando o $\mathrm{pH}$ ruminal é menor que 5,6 por mais de uma hora (GOZHO et al., 2005). Dietas ricas em amido acarretam em reduções prolongadas no $\mathrm{pH}$ ruminal, facilitando o crescimento de bactérias amilolíticas, enquanto as bactérias celulolíticas e digestibilidade da FDN são simultaneamente inibidos. Além disso, a maior inclusão de concentrado na dieta diminui a ruminação (Tabela 5) e, consequentemente, o tamponamento através da saliva.

A concentração de ácidos graxos de cadeia curta no fluido ruminal é reflexo 
Rev. Bras. Saúde Prod. Anim., Salvador, v.16, n.1, p.118-129 jan./mar., 2015 http://www.rbspa.ufba.br ISSN 15199940

da quantidade de ácidos produzido e absorvido (BANNINK et al., 2012), do volume de líquido ruminal e $\mathrm{pH}$ (BANNINK et al., 2008), área de absorção da parede do rúmen $\mathrm{e}$ proliferação epitelial (PENNER et al., 2011).

A produção estacional de forragem é um fato concreto, que tem causado enormes prejuízos à pecuária, pois a maioria dos produtores não se prepara para suplementar os rebanhos no período de escassez. A moagem da cana-de-açúcar e consequente produção do bagaço acontecem justamente nesse período crítico, no qual falta alimento para os animais, ocorrendo, na maioria das vezes, perda de peso (MURTA et al., 2011). Maiores proporções de concentrado associado ao bagaço de cana-de-açúcar in natura podem ser utilizadas em dietas para ovinos, pois aumentam o consumo de nutrientes, principalmente de energia, sem causar prejuízos para a saúde ruminal e, consequentemente do animal. Sugere-se a condução de trabalhos com animais em produção.

\section{REFERÊNCIAS}

BANNINK, A.; FRANCE, J.; LOPEZ, S. GERRITS, W.J.J.; KEBREAB, E.; TAMMINGA, S.; DIJKSTRA, J. Modelling the implications of feeding strategy on rumen fermentation and functioning of the rumen wall. Animal Feed Science and Technology, v.143, n.1-4, p.3-26, 2008.

BANNINK, A.; GERRITS, W.J.J.; FRANCE, J.; DIJKSTRA, J. Variation in rumen fermentation and the rumen wall during the transition period in dairy cows. Animal Feed Science and Technology, v.172, n.1/2, p.80-94, 2012.
CASALI, A.O.; DETMANN, E.; VALADARES FILHO, S.C.; PEREIRA, J.C.; CUNHA, M. DA; DETMANN, K.S.C.; PAULINO, M.F. Estimação de teores de componentes fibrosos em alimentos para ruminantes em sacos de diferentes tecidos. Revista Brasileira de Zootecnia, v.38, n.1, p.130-138, 2009.

CHIZZOTTI, F.H.M., O.G., PEREIRA, VALADARES FILHO' S.C.; TEDESCHI L.O.; RIBEIRO; K.G.; PEREIRA, D.H. Intake, digestibility, and performance of steers fed diets based on two corn silage hybrids and two concentrate levels.

Arquivo Brasileiro de Medicina Veterinária e Zootecnia, v.62, n.4, p.868-874, 2010.

CABRAL, L.S.I; VALADARES FILHO, S.C.; DETMANN, E.; ZERVOUDAKIS, J.T.; GALATI, R.L.; SOUSA, D.P.; SOUZA, A.L. Simulation and validation of the ruminal digestion of carbohydrates in cattle from kinetic parameters obtained by in vitro gas production technique.

Revista Brasileira de Zootecnia, v.40, n.9, p.1984-1990, 2011.

DETMAN, E.; SOUZA, M.A.; VALADARES FILHO, S.C. Métodos para análise de alimentos. Visconde do Rio Branco, MG: Suprema, 2012. 214p.

DETMANN, E.; VALADARES FILHO, S.C. On the estimation of non-fibrous carbohydrates in feeds and diets. Arquivo Brasileiro de Medicina Veterinária e Zootecnia, v.62, n.4, p.980-984, 2010.

DIJKSTRA, J.; ELLIS, J.L.; KEBREAB A, E.; STRATHE, A.B.; LÓPEZ, S.; FRANCE, J.; BANNINK, A. Ruminal $\mathrm{pH}$ regulation and nutritional consequences of low pH. Animal Feed Science and Technology, v.172, p.2233, 2012. 
Rev. Bras. Saúde Prod. Anim., Salvador, v.16, n.1, p.118-129 jan./mar., 2015 http://www.rbspa.ufba.br ISSN 15199940

FERREIRA, M.A.; SILVA, F.M.; BISPO, S.V.; AZEVEDO, M.

Estratégias na suplementação de vacas leiteiras no semi-árido do Brasil.

Revista Brasileira de Zootecnia, v.38, p.322-329, 2009. Supl. especial.

FUKUSHIMA, R.S.; SAVIOLI, N.M.F. Correlação entre digestibilidade in vitro da parede celular e três métodos analíticos para a avaliação quantitativa da lignina. Revista Brasileira de Zootecnia, v.30, n.2, p.302-309, 2001.

GOUVEIA, E.R.; NASCIMENTO, R.T.; SOUTO-MAIO, A.M. Validação de metodologia para a caracterização química de bagaço de cana-de-açúcar. Química Nova, v.32, n.6, p.1500-1503, 2009.

GOZHO, G. N., PLAIZIER, J. C.; KRAUSE, D. O.; KENNEDY, A. D.; WITTENBERG, K.M. Subacute ruminal acidosis induces ruminal lipopolysaccharide endotoxin release and triggers an inflammatory response.

Journal of Dairy Science, v.88, n.4, p.1399-1403, 2005.

JOHNSON, T.R.; COMBS, D.K. Effects of prepartum diete, inert rumen bulk, and dietary polyethylene glycol on dry matter intake of lactating dairy cows. Journal of Dairy Science, v.74, n.3, p. 933-944, 1991.

MENDES, C.Q.; TURINO, V.F.; SUSIN, I.; PIRES, A.V.; MORAIS, J.B.; GENTIL, R.S. Comportamento ingestivo de cordeiros e digestibilidade dos nutrientes de dietas contendo alta proporção de concentrado e diferentes fontes de fibra em detergente neutro.

Revista Brasileira de Zootecnia, v.39, p.594-600, 2010.
MERTENS, D.R. Creating a system for meeting the fiber requirements of dairy cows. Journal of Dairy Science, v.80, p.1463-1481, 1997.

MERTENS, D.R.; LOFTEN, J.R. The effects of starch on forage fiber digestion kinetics in vitro. Journal of Dairy Science, v.63, p. 1437, 1980.

MOULD, F.L.; ORSKOV, E.R.; MANN, S.O. Associative effects of mixed feeds. I. Effects of type and level of supplementation and the influence of the rumen fluid $\mathrm{pH}$ on cellulolysis in vivo and dry matter digestion of various roughages. Animal Feed Science and Technology, v.10, p.15-30, 1983.

MORENO, G.M.B.; SILVA SOBRINHO, A.G.; LEÃO, A.G.; LOUREIRO, C.M.B.; PEREZ, H.L.; ROSSI, R.C. Desempenho, digestibilidade e balanço de nitrogênio em cordeiros alimentados com silagem de milho ou cana-de-açúcar e dois níveis de concentrado. Revista Brasileira de Zootecnia, v.39, n.4, p.853-860, 2010.

MOURINO, F.; AKKARAWONGSA, R.A.; WEIMER, P.J. Initial $\mathrm{pH}$ as a determinant of cellulose digestion rate by mixed ruminal microorganisms in vitro. Journal of Dairy Science, v.84, n.4, p. 848-859, 2001.

MURTA, R.M.; CHAVES, M.A.; PIRES, A.J.V.; VELOSO,C.M.; SILVA,F.F.D.; NETO, R.; SANTOS, P.E.F.D. Performance and nutrients apparent digestibility in sheep fed diets containing sugar cane bagasse treated with calcium oxide. Revista Brasileira de Zootecnia, v.40, n.6, p.1325-1332, 2011. 
Rev. Bras. Saúde Prod. Anim., Salvador, v.16, n.1, p.118-129 jan./mar., 2015 http://www.rbspa.ufba.br ISSN 15199940

OLIVEIRA, A.S.; DETMANN, E.; CAMPOS, J.M.S.; PINA, D.S.; SOUZA, S.M.; COSTA, M.G. Metaanálise do impacto da fibra em detergente neutro sobre o consumo, digestibilidade e desempenho de vacas leiteiras em lactação. Revista

Brasileira de Zootecnia, v.40, n.7, p.1587-1595, 2011.

PALMONARI, A.; STEVENSON, D.M.; MERTENS, D.R.; CRUYWAGEN, C.W.; WEIMER, P.J. $\mathrm{pH}$ dynamics and bacterial community composition in the rumen of lactating dairy cows. Journal of Dairy Science, v.93, n.1, p.279-287, 2010.

PENNER, G.B.; STEELE, M.A.; ASCHENBACH, J.R.; MCBRIDE, B.W. Molecular adaptation of ruminal epithelia to highly fermentable diets.

Journal of Animal Science, v.89, n.4, p.1108-1119, 2011.

SAMPAIO, C.B.; DETMANN, E.; LAZZARINI, I.; SOUZA, M.A.; PAULINO, M.F.; VALADARES FILHO, S.C. Rumen dynamics of neutral detergent fiber in cattle fed lowquality tropical forage and supplemented with nitrogenous compounds. Revista Brasileira de Zootecnia, v.38, n.3, p.560-569, 2009.

SANTELLO, G.A.; MACEDO, F.A.F.; MEXIA, A.G.; SAKAGUTI, E.S.; DIAS, F.J.; PEREIRA, M.F. Características de carcaça e análise do custo de sistemas de produção de cordeiras $1 / 2$ Dorset Santa Inês. Revista Brasileira de Zootecnia, v.35, p.10091015, 2006.
SNIFFEN, C.J.; O'CONNOR, J.D.; VAN SOEST, P.J.; FOX, D.G; RUSSELL, J.B. A net carbohydrate and protein system for evaluating cattle diets:II. Carbohydrate and protein availability. Journal of Animal Science, v.70, n.11, p.35623577, 1992.

\section{STATISTICAL ANALYSES}

SYSTEM. SAS/STAT user's guide. Version 9.0 Cary, SAS Institute, 2002.

TEIXEIRA, F. A.; PIRES, A.V.; NASCIMENTO.P.V.N. Bagaço de cana-de-açúcar na alimentação de bovinos (Sugarcane pulpin the feeding of bovine). REDVET - Revista Electrónica de Veterinária, v.8, n.6, p.1-9, 2007.

TRIPATHI, M.K.; CHATURVEDI, O.H.; KARIM S.A.; SINGH, V.K.; SISODIYA, S.L. Effect of different levels of concentrate allowances on rumen fluid $\mathrm{pH}$, nutrient digestion, nitrogen retention and growth performance of weaner lambs. Small Ruminant Research, v.72, n.1, p.178186, 2007.

WELCH, J.G. Rumination, particle size and passage from the rumen. Journal of Animal Science, v.54, n.4, p.885-894, 1982.

Data de recebimento: 30/05/2014

Data de aprovação: 17/03/2015 